\title{
Thermal stability of plasma-nitrided aluminum oxide films on $\mathrm{Si}$
}

\author{
K. P. Bastos, R. P. Pezzi, L. Miotti, G. V. Soares, C. Driemeier, and J. Morais \\ Instituto de Física-UFRGS, CP 15051 Porto Alegre 91501-970-Brazil \\ I. J. R. Baumvol \\ Centro de Ciencias Exatas e Tecnologicas-UCS, Av. Francisco G. Vargas 1130, \\ 95070-560 Caxias do Sul-Brazil \\ C. Hinkle and G. Lucovsky \\ Department of Physics, North Carolina State University, Raleigh, North Carolina 27695-8202
}

(Received 8 September 2003; accepted 12 November 2003)

\begin{abstract}
The effect of post-deposition rapid thermal annealing in vacuum and in dry $\mathrm{O}_{2}$ on the stability of remote plasma-assisted nitrided aluminum oxide films on silicon is investigated. The areal densities of $\mathrm{Al}, \mathrm{O}, \mathrm{N}$, and $\mathrm{Si}$ were determined by nuclear reaction analysis and their concentration versus depth distributions by narrow nuclear reaction resonance profiling, with subnanometric depth resolution. Annealing in both vacuum and $\mathrm{O}_{2}$ atmospheres produced partial loss of $\mathrm{N}$ from the near-surface regions of the films and its transport into near-interface regions of the Si substrate. Oxygen from the gas phase was incorporated in the $\mathrm{AlON}$ films in exchange for $\mathrm{O}$ and $\mathrm{N}$ previously existing therein, as well as in the near-interface regions of the Si substrate, leading to oxynitridation of the substrate. Al and $\mathrm{Si}$ remained essentially immobile under rapid thermal processing, confirming that the presence of nitrogen improves the thermal stability characteristics of the AlON/ $\mathrm{Si}$ structures in comparison with non-nitrided $\mathrm{Al}_{2} \mathrm{O}_{3} / \mathrm{Si}$. (C) 2004 American Institute of Physics.
\end{abstract}

[DOI: $10.1063 / 1.1638629$ ]

The use of metal oxide and silicate films on $\mathrm{Si}$ as a high$k$ replacement for silicon dioxide and oxynitride gate dielectrics in advanced very large scale integration technology presents several difficulties concerning the density of interface states, reliability, chemical and structural (crystallization) stability in further processing steps, oxidation of the Si substrate, migration of boron and metallic species into the active semiconductor region, transport of Si into the high- $k$ film, and formation of voids. ${ }^{1-3}$ Recent investigations ${ }^{4-9}$ indicated that incorporation of nitrogen into aluminum, zirconium, and hafnium oxide and silicate films, either during or after deposition, by plasma or thermal processing, provided substantial improvements in the direction of overcoming the abovementioned difficulties, in addition to lower leakage current density. However, since $\mathrm{N}$ is mainly incorporated into metastable configurations in these oxide and silicate films, ${ }^{4,8,10}$ their integration into the metal-oxide-semiconductor fieldeffect transistor fabrication process flow relies on the particular characteristics of $\mathrm{N}$ incorporation (concentrations and profiles) and its stability in the materials during further processing steps. Among the relevant thermal steps, there is special interest in Si-dopants annealing which is accomplished by rapid thermal annealing (RTA) at temperatures as high as $1000^{\circ} \mathrm{C}$ or more, as well as in annealing in oxygen containing atmospheres. Indeed, structural degradation, more specifically crystallization of the amorphous high- $k$ film, was observed $^{6,7}$ in those regions of the high- $k$ film from where $\mathrm{N}$ was lost during post-deposition thermal processing. Degradation of the electrical properties ${ }^{10,11}$ (lower capacitance) also resulted from $\mathrm{N}$ loss.

We report here on atomic scale stability studies, as investigated by determining the transport and exchange of $\mathrm{N}$, $\mathrm{O}, \mathrm{Al}$, and $\mathrm{Si}$ atoms during RTA of 6 or $12 \mathrm{~nm}$ thick alumi- num oxide $\left(\mathrm{Al}_{2} \mathrm{O}_{3}\right)$ films deposited on $\mathrm{Si}(001)$ by remote plasma-enhanced chemical vapor deposition, ${ }^{4,12}$ followed by remote plasma-assisted nitridation (RPN ${ }^{13}$ in ${ }^{15} \mathrm{~N}_{2}$. These structures $(\mathrm{AlON} / \mathrm{Si})$ were submitted to the following RTA sequences: vacuum $\left(1 \times 10^{-7} \mathrm{mbar}\right)$ at $600{ }^{\circ} \mathrm{C}$ for $60 \mathrm{~s}$, or vacuum at $1000{ }^{\circ} \mathrm{C}$ for $10 \mathrm{~s}$, or $7 \mathrm{mbar}$ of $97 \%{ }^{18} \mathrm{O}$-enriched $\mathrm{O}_{2}\left({ }^{18} \mathrm{O}_{2}\right)$ at $1000^{\circ} \mathrm{C}$ for $10 \mathrm{~s}$, or vacuum at $600^{\circ} \mathrm{C}$ for $60 \mathrm{~s}$ followed by ${ }^{18} \mathrm{O}_{2}$ at $1000{ }^{\circ} \mathrm{C}$ for $10 \mathrm{~s}$. The aim of the present study is an atomic scale observation and understanding of the possible consequences of rapid thermal processing, like $\mathrm{O}$, $\mathrm{N}$, and $\mathrm{Al}$ migration and loss from the films, as well as incorporation of $\mathrm{O}$ from the gas phase into the films, and $\mathrm{Si}$ migration from the substrate into the AlON films and eventual incorporation therein. The results will be compared with previous results obtained in non-nitrided $\mathrm{Al}_{2} \mathrm{O}_{3}$. 3,14,15

The areal densities of ${ }^{15} \mathrm{~N},{ }^{16} \mathrm{O},{ }^{18} \mathrm{O}$, and ${ }^{27} \mathrm{Al}$ were determined by nuclear reaction analysis in plateau regions of the cross-section curves using the ${ }^{15} \mathrm{~N}(\mathrm{p}, \alpha \gamma){ }^{12} \mathrm{C}$, ${ }^{16} \mathrm{O}(\mathrm{d}, \mathrm{p}){ }^{17} \mathrm{O}$, and ${ }^{18} \mathrm{O}(\mathrm{p}, \alpha){ }^{15} \mathrm{~N}$ reactions, respectively, ${ }^{16}$ and the resonance at $992 \mathrm{keV}$ in the ${ }^{27} \mathrm{Al}(\mathrm{p}, \gamma){ }^{28} \mathrm{Si} .{ }^{17}$ The profiles of ${ }^{15} \mathrm{~N},{ }^{18} \mathrm{O},{ }^{27} \mathrm{Al}$, and ${ }^{29} \mathrm{Si}$ were determined with subnanometric depth resolutions by nuclear narrow resonant reaction profiling using the ${ }^{15} \mathrm{~N}(\mathrm{p}, \alpha \gamma){ }^{12} \mathrm{C}, \quad{ }^{18} \mathrm{O}(\mathrm{p}, \alpha){ }^{15} \mathrm{~N}$, ${ }^{27} \mathrm{Al}(\mathrm{p}, \gamma){ }^{28} \mathrm{Si}$, and ${ }^{29} \mathrm{Si}(\mathrm{p}, \gamma){ }^{30} \mathrm{P}$ reactions, near the resonances at $429,151,404.9$, and $414 \mathrm{keV}$, respectively. ${ }^{16,18}$ The excitation curves (yield versus incident proton energy) obtained by NRP provide the depth distributions of the isotopes, since as the proton beam energy is increased deeper regions in the films are sampled. ${ }^{16}$

The areal densities given in Table I indicate that RPN leads to incorporation of ${ }^{15} \mathrm{~N}$ into the AlON/Si films, whereas RTA leads to the partial loss of ${ }^{15} \mathrm{~N}$ from these structures. ${ }^{18} \mathrm{O}_{2}$-annealing produces a larger $\mathrm{N}$ loss as compared to 
TABLE I. Areal densities (in units of $10{ }^{15} \mathrm{~cm}^{-2}$ ) of ${ }^{15} \mathrm{~N},{ }^{18} \mathrm{O},{ }^{16} \mathrm{O}$, and ${ }^{27} \mathrm{Al}$ in the AlON films on $\mathrm{Si}(001)$ as determined by nuclear reaction analysis. Typical errors are $5 \%$ for ${ }^{15} \mathrm{~N}$ and ${ }^{18} \mathrm{O}$ and $10 \%$ for ${ }^{16} \mathrm{O}$ and ${ }^{27} \mathrm{Al}$.

\begin{tabular}{|c|c|c|c|c|c|c|c|c|}
\hline \multirow[b]{2}{*}{ Sample } & \multicolumn{2}{|c|}{${ }^{15} \mathrm{~N}$} & \multicolumn{2}{|c|}{${ }^{18} \mathrm{O}$} & \multicolumn{2}{|c|}{${ }^{16} \mathrm{O}$} & \multicolumn{2}{|c|}{${ }^{27} \mathrm{Al}$} \\
\hline & $6 \mathrm{~nm}$ & $12 \mathrm{~nm}$ & $6 \mathrm{~nm}$ & $12 \mathrm{~nm}$ & $6 \mathrm{~nm}$ & $12 \mathrm{~nm}$ & $6 \mathrm{~nm}$ & $12 \mathrm{~nm}$ \\
\hline As-prepared & 2.3 & 2.7 & 0.2 & 0.4 & 37.7 & 71.2 & 49.6 & 97.1 \\
\hline Vacuum $600^{\circ} \mathrm{C}, 60 \mathrm{~s}$ & 2.1 & 2.2 & - & - & 37.3 & 72.0 & 48.3 & 101.3 \\
\hline Vacuum $1000^{\circ} \mathrm{C}, 10 \mathrm{~s}$ & 1.7 & 1.7 & - & - & 37.9 & 72.2 & 47.7 & 96.1 \\
\hline${ }^{18} \mathrm{O}_{2} 1000{ }^{\circ} \mathrm{C}, 10 \mathrm{~s}$ & 1.5 & 1.4 & 14.5 & 15.5 & 23.7 & 57.8 & 51.3 & 102.7 \\
\hline Vacuum, $600{ }^{\circ} \mathrm{C}, 60 \mathrm{~s}+{ }^{18} \mathrm{O}_{2}, 1000^{\circ} \mathrm{C}, 10 \mathrm{~s}$ & 1.2 & 1.3 & 9.5 & 10.3 & 28.1 & 61.9 & 48.6 & 99.9 \\
\hline
\end{tabular}

vacuum-annealing and the (vacuum $+{ }^{18} \mathrm{O}_{2}$ )-annealing sequence an even larger $\mathrm{N}$ loss. The roughly constant values (within experimental errors) of the $\left({ }^{18} \mathrm{O}+{ }^{16} \mathrm{O}\right)$ areal densities indicate that ${ }^{18} \mathrm{O}$ from the gas phase is incorporated during ${ }^{18} \mathrm{O}_{2}$ or (vacuum $+{ }^{18} \mathrm{O}_{2}$ ) -annealing in replacement for ${ }^{16} \mathrm{O}$ previously existing in the AlON/Si structures. A small fraction of the ${ }^{18} \mathrm{O}$ atoms may be incorporated in exchange for ${ }^{15} \mathrm{~N}$ atoms as discussed below. Finally, Table I shows that the ${ }^{27} \mathrm{Al}$ areal densities remain constant within experimental errors for all annealing routes.

Figure 1 shows the ${ }^{15} \mathrm{~N}$ and ${ }^{18} \mathrm{O}$ excitation curves and profiles for the as-deposited and nitrided samples and for these samples processed in the different annealing routes. One can see that the ${ }^{15} \mathrm{~N}$ loss takes place mostly from the near surface regions of the AlON films, the loss from the bulk regions of the films being moderate whereas the nearinterface ${ }^{15} \mathrm{~N}$ concentrations change only slightly. In all annealed samples, slightly deeper ${ }^{15} \mathrm{~N}$ profiles reveal that the near interface regions of the $\mathrm{Si}(001)$ substrates are nitrided. In the initially $6 \mathrm{~nm}$ thick AlON films, ${ }^{15} \mathrm{~N}$ piles-up in the near-interface regions after either vacuum or ${ }^{18} \mathrm{O}_{2}$ annealings at $1000^{\circ} \mathrm{C}$, whereas for the vacuum at $600^{\circ} \mathrm{C}$ for $60 \mathrm{~s}$ or vacuum at $600^{\circ} \mathrm{C}$ for $60 \mathrm{~s}$ followed by ${ }^{18} \mathrm{O}_{2}$ at $1000^{\circ} \mathrm{C}$ for $10 \mathrm{~s}$ there is substantially lower pile-up.

${ }^{18} \mathrm{O}$ is incorporated along the whole AlON films, similar

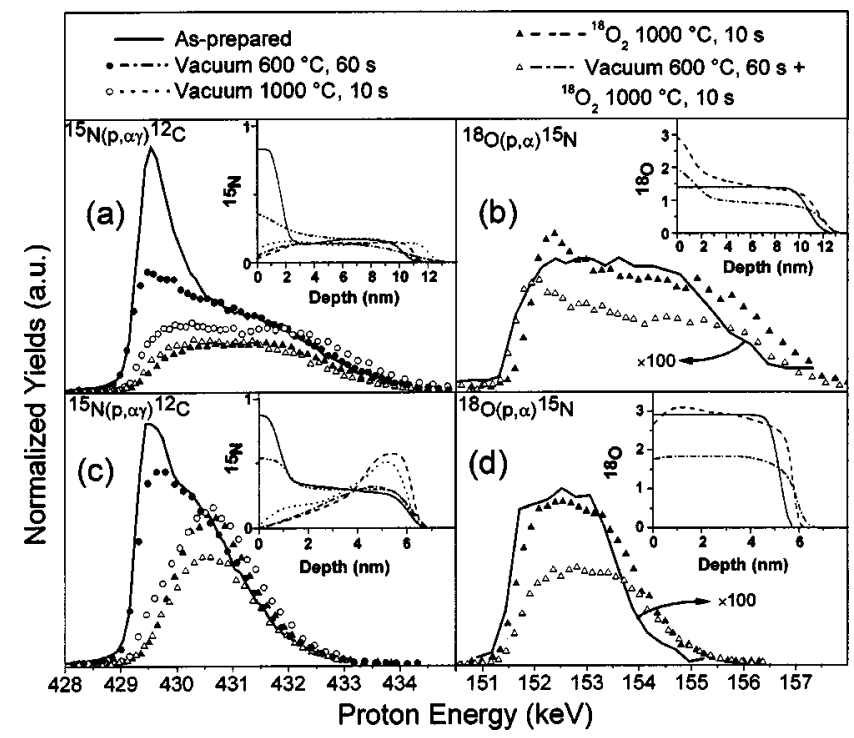

FIG. 1. Excitation curves of the ${ }^{15} \mathrm{~N}(\mathrm{p}, \alpha \gamma){ }^{12} \mathrm{C}$ and ${ }^{18} \mathrm{O}(\mathrm{p}, \alpha){ }^{15} \mathrm{~N}$ nuclear reactions near the resonances at 429 and $151 \mathrm{keV}$, respectively, from asdeposited $\mathrm{AlO}^{15} \mathrm{~N}$ samples (solid lines) and from samples submitted to RTA (a) and (b): initial thickness of $12 \mathrm{~nm}$; (c) and (d), initial thickness of $6 \mathrm{~nm}$. The corresponding profiles are shown in the insets, with ${ }^{15} \mathrm{~N}$ and ${ }^{18} \mathrm{O}$ concentrations in units of $10^{22} \mathrm{~cm}^{-3}$. centrations in units of $10^{22} \mathrm{~cm}^{-3}$. $10^{22} \mathrm{~cm}^{-3}$. The symbols are the same as in Fig. 1 .
Downloaded 22 Feb 2008 to 152.1 .190 .114 . Redistribution subject to AlP license or copyright; see http://apl.aip.org to previous investigations performed in non-nitrided $\mathrm{Al}_{2} \mathrm{O}_{3} / \mathrm{Si}{ }^{14,15}$ This means that the same mechanisms are in force, namely, a propagating ${ }^{18} \mathrm{O}$ front from the surface that interacts with the AlON network. Accumulation of ${ }^{18} \mathrm{O}$ in near-surface regions, from where most of the ${ }^{15} \mathrm{~N}$ losses take place, indicates that part of the ${ }^{18} \mathrm{O}$ atoms are incorporated in exchange for ${ }^{15} \mathrm{~N}$. Incorporation of ${ }^{18} \mathrm{O}$ in near-interface regions of the $\mathrm{Si}(001)$ substrate (although much smaller than in previous studies ${ }^{3,14}$ ) together with the above-described ${ }^{15} \mathrm{~N}$ incorporation in these regions, reveal the oxynitridation of the substrate. The thickness of the silicon oxynitride interlayer is not in excess to $0.5 \mathrm{~nm}$.

The ${ }^{27} \mathrm{Al}$ excitation curves and profiles are shown in Fig. 2 , indicating that there is neither redistribution nor loss of aluminum in the AlON/Si structures under thermal processing. Previous results ${ }^{19}$ indicated that $\mathrm{N}$ incorporation would provide a diffusion barrier, since a $1 \mathrm{~nm}$ thick silicon oxynitride interlayer between $\mathrm{Al}_{2} \mathrm{O}_{3}$ films and the Si substrate partially prevented diffusion of $\mathrm{Al}$ into the $\mathrm{Si}$ substrate. In the present work the diffusion barrier is more effective owing probably to the fact that $\mathrm{N}$ is incorporated into the whole film. The ${ }^{29} \mathrm{Si}$ excitation curves for the as-prepared samples and for the samples annealed in ${ }^{18} \mathrm{O}_{2}$ at $1000{ }^{\circ} \mathrm{C}$ for $10 \mathrm{~s}$ are shown in Fig. 3. The rough superposition of the excitation curves for the as-prepared and for the ${ }^{18} \mathrm{O}_{2}$-annealed curves indicates that there is essentially no migration of $\mathrm{Si}$ from the substrate into the AlON film (within the sensitivity of the technique). Migration of $\mathrm{Si}$ would lead to an increase in the gamma yield toward the resonance energy. The absence of $\mathrm{Al}$

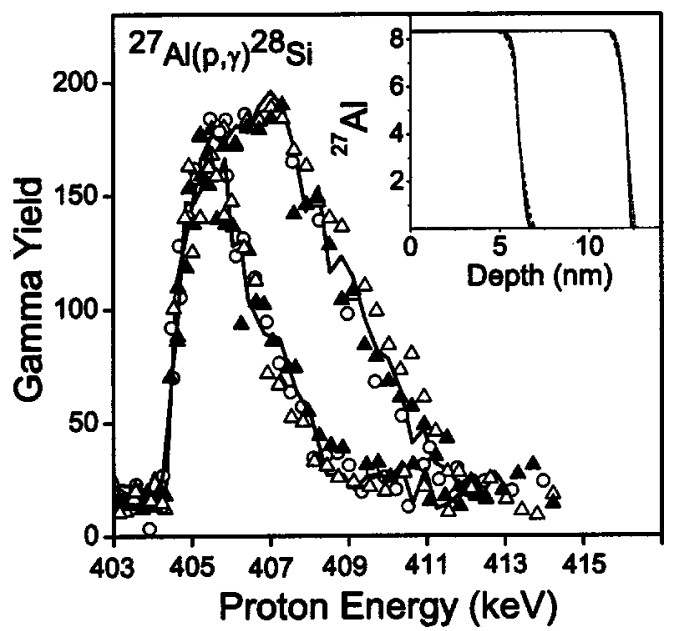

FIG. 2. Excitation curves of the ${ }^{27} \mathrm{Al}(\mathrm{p}, \gamma)^{28} \mathrm{Si}$ nuclear reaction near the resonance at $404.9 \mathrm{keV}$ from the same samples as in Fig. 1. The corresponding profiles are shown in the insets, with ${ }^{27} \mathrm{Al}$ concentrations in units of 


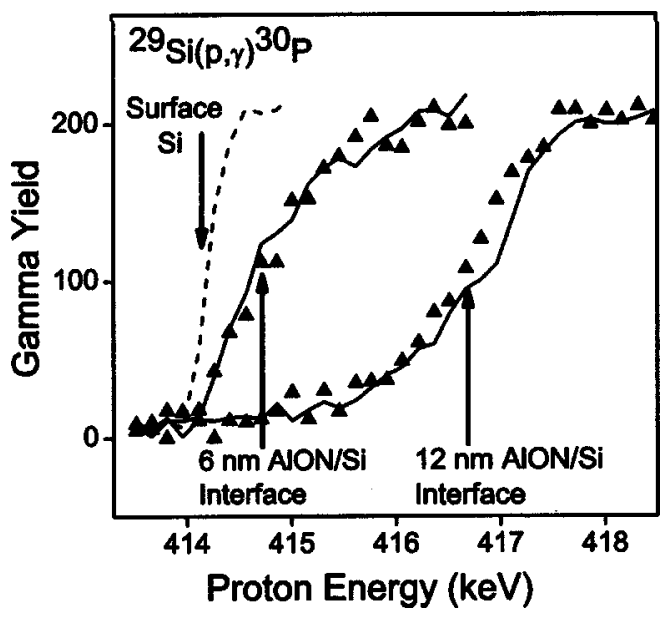

FIG. 3. Excitation curves of the ${ }^{29} \mathrm{Si}(\mathrm{p}, \gamma){ }^{30} \mathrm{P}$ nuclear reaction near the resonance at $414 \mathrm{keV}$. Solid lines: as-deposited and plasma-nitrided 6 and $12 \mathrm{~nm}$ AlON films on $\mathrm{Si}$; solid triangles: RTA in ${ }^{18} \mathrm{O}_{2}$ at $1000{ }^{\circ} \mathrm{C}$ for $10 \mathrm{~s}$. An excitation curve from a HF-cleaned $\mathrm{Si}$ wafer is also shown (dashed line). The arrows indicate the energy positions of ${ }^{29} \mathrm{Si}$ at the $\mathrm{Si}$ surface and at the AlON/Si interfaces.

and Si transport during annealing here observed is in strong contrast with previous observations in non-nitrided $\mathrm{Al}_{2} \mathrm{O}_{3}$ films on $\mathrm{Si}^{14,20}$

In summary, remote plasma-assisted nitridation of 6 and $12 \mathrm{~nm}$ aluminum oxide films deposited on $\mathrm{Si}(001)$ led to heavy nitridation of the near-surface regions of the films and rather light nitridation of the bulk and near-interface regions. The incorporation of nitrogen has rendered the AlON films far more stable against thermal processing, either in vacuum or in $\mathrm{O}_{2}$ atmospheres, than the non-nitride $\mathrm{Al}_{2} \mathrm{O}_{3}$ films studied previously, justifying the reported improvements on reliability and electrical characteristics. The most important features of the improved stability were (i) there is no loss of $\mathrm{Al}$ from the films, (ii) there is also no change of composition (and consequently of dielectric constant) of the films owing to migration of Si from the substrate, and (iii) the oxidation (oxynitridation in the present case) of the $\mathrm{Si}$ substrate is much smaller in $\mathrm{AlON}$ than in $\mathrm{Al}_{2} \mathrm{O}_{3}$ films, resulting in a thinner intermediate silicon oxynitride layer and therefore in a smaller reduction of the overall capacitance due to series association of dielectrics. The main atomic transport and exchange facts observed during RTA were (i) the loss of N, mostly from near-surface and bulk regions of the films, and the migration of part of the $\mathrm{N}$ atoms across the AlON films into the near-interface layers of the $\mathrm{Si}$ substrate, leading to nitridation of the substrate, (ii) the incorporation of oxygen from the gas phase into the whole AlON films in exchange for previously existing $\mathrm{O}$ and $\mathrm{N}$, and (iii) the transport of $\mathrm{O}$, besides of $\mathrm{N}$, into the $\mathrm{Si}$ substrate, leading to the formation of a $\mathrm{SiON}$ intermediate layer. Investigations on the chemical status of $\mathrm{N}$ in the AlON films of the present work before and after RTA are in progress using angle-resolved x-ray photoelectron spectroscopy.

${ }^{1}$ G. D. Wilk, R. M. Wallace, and J. M. Anthony, J. Appl. Phys. 89, 5243 (2001).

${ }^{2}$ A. Kingon, J.-P. Maria, and S. K. Streiffer, Nature (London) 406, 1032 (2000).

${ }^{3}$ M. Copel, E. Cartier, E. P. Gusev, S. Guha, N. Bojarczuck, and M. Poppeler, Appl. Phys. Lett. 78, 2670 (2001).

${ }^{4}$ C. Hinkle and G. Lucovsky, Appl. Surf. Sci. 216, 124 (2003).

${ }^{5}$ M. S. Akbar, S. Gopalan, H.-J. Cho, K. Onishi, R. Choi, R. Nieh, C. S. Kang, Y. H. Kim, J. Han, S. Krishnan, and J. C. Lee, Appl. Phys. Lett. 82, 1757 (2003).

${ }^{6}$ M. Quevedo-Lopez, M. El-Bouanani, M. J. Kim, B. E. Gnade, R. M. Wallace, M. R. Visokay, A. LiFatou, J. J. Chambers, and L. Colombo, Appl. Phys. Lett. 82, 4669 (2003).

${ }^{7}$ M. R. Visokay, J. J. Chambers, A. L. P. Rotondaro, A. Shanware, and L. Colombo, Appl. Phys. Lett. 80, 3183 (2002).

${ }^{8}$ K. P. Bastos, J. Morais, L. Miotti, R. P. Pezzi, G. V. Soares, I. J. R. Baumvol, H.-H. Tseng, R. I. Hegde, and P. J. Tobin, Appl. Phys. Lett. 81, 1669 (2002).

${ }^{9}$ M. Koyama, A. Kaneko, T. Ino, M. Koike, Y. Kamata, R. Iijima, Y. Kamimuta, A. Takashima, M. Suzuki, C. Hongo, S. Inumiya, M. Takayanagi, and A. Nishiyama, Tech. Dig.-Int. Electron Devices Meet. 2002, 235 (2002).

${ }^{10}$ C. S. Kang, H.-J. Cho, K. Onishi, R. Nieh, R. Choi, S. Gopalan, S Krishnan, J. H. Han, and J. C. Lee, Appl. Phys. Lett. 81, 2593 (2002).

${ }^{11}$ C. S. Kang, H.-J. Cho, K. Onishi, R. Choi, R. Nieh, S. Gopalan, S. Krishnan, and J. C. Lee, 2002 Symposium on VLSI Technology Digest of Technical Papers (IEEE, Piscataway, NJ, 2002), p. 146.

${ }^{12}$ G. B. Rayner, Jr, D. Kang, Y. Zhang, and G. Lucovsky, J. Vac. Sci. Technol. B 20, 1748 (2002).

${ }^{13}$ H. Nimi, A. Khandelwal, H. H. Lamb, and G. Lucovsky, J. Appl. Phys. 91, 48 (2002).

${ }^{14}$ C. Krug, E. B. O. da Rosa, R. M. C. de Almeida, J. Morais, I. J. R. Baumvol, T. D. M. Salgado, and F. C. Stedile, Phys. Rev. Lett. 85, 4120 (2000).

${ }^{15}$ E. B. O. da Rosa, I. J. R. Baumvol, J. Morais, R. M. C. de Almeida, R. M. Papaleo, and F. C. Stedile, Phys. Rev. B 86, 12130 (2002).

${ }^{16}$ I. J. R. Baumvol, Surf. Sci. Rep. 36, 1 (1999).

${ }^{17}$ M. Frank, Y. Chabal, M. L. Green, A. Delabie, B. Brijs, E. B. O. da Rosa, I. J. R. Baumvol, and F. C. Stedile, Appl. Phys. Lett. 83, 740 (2003).

${ }^{18}$ E. Gusev, M. Copel, E. Cartier, I. J. R. Baumvol, C. Krug, and M. A. Gribelyuk, Appl. Phys. Lett. 76, 176 (2000).

${ }^{19}$ S. Guha, E. P. Gusev, H. Okorn-Schmidt, M. Copel, L.-A. Ragnarsson, and P. Ronsheim, Appl. Phys. Lett. 81, 2956 (2002).

${ }^{20}$ M. Copel, Phys. Rev. Lett. 86, 4713 (2001). 